\title{
CONTAMINAÇÃO POR ESPÉCIES METÁLICAS EM SOLOS ASSOCIADOS ÀS RODOVIAS: BOTUCATU-SP
}

\author{
CONTAMINATION BY METALLIC SPECIES IN ASSOCIATED SOILS NEAR HIGHWAYS: \\ BOTUCATU-SP.
}

\section{Ivalde BELLUTA ${ }^{1}$, Júlio Toshimi DOYAMA ${ }^{1}$, José Carlos COELHO ${ }^{2}$, Sílvio Alexandre de JESUS $^{2}$, Marcos Henrique Pereira WONDRACEK ${ }^{3}$, Lídia Raquel de CARVALHO ${ }^{1}$, Gustavo Rocha de CASTRO ${ }^{1}$}

${ }^{1}$ Universidade Estadual Paulista (UNESP). Instituto de Biociências, Botucatu - SP. Emails: ibelluta@ibb.unesp.br; julio@ibb.unesp.br; lidiarc@ibb.unesp.br; castrogr@ibb.unesp.br

${ }^{2}$ Universidade Estadual Paulista (UNESP). Fazenda Experimental Lageado, Botucatu SP. Email: jccoelho@fca.unesp.br

${ }^{3}$ Universidade Federal da Grande Dourados. Dourados - MS. Email: marcoswondracek@gmail.com

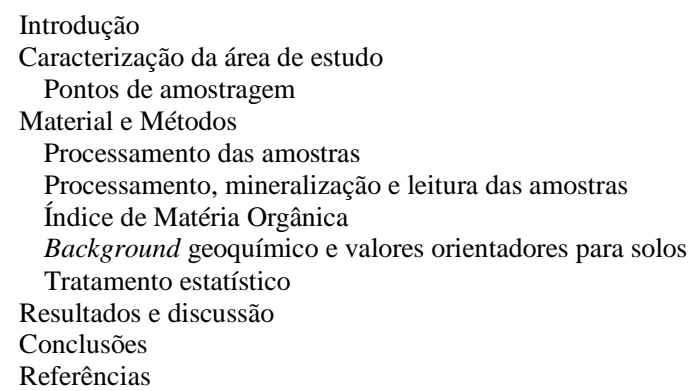

RESUMO - Devido ao fluxo de veículos nas rodovias Domingos Sartori e Marechal Rondon (Botucatu-SP) e à possível contaminação de mananciais adjacentes, realizou-se estudo de monitoramento de espécies metálicas em solos da região. Esse estudo buscou determinar concentrações de $\mathrm{Cd}, \mathrm{Pb}, \mathrm{Cu}, \mathrm{Co}, \mathrm{Cr}, \mathrm{Ni}, \mathrm{Zn}$ e Sb, verificar a relação destes metais com a matéria orgânica e identificar fontes de contaminação. As espécies metálicas foram determinadas com espectrômetro de emissão atômica com plasma acoplado indutivamente. Os resultados foram avaliados com teste de Tukey. Como resultado, obtiveram-se concentrações de 1,2 a 11,0 vezes maiores no $P_{2}$ em relação ao $P_{1}$. Nos pontos de amostragem mais próximos e nos mais distantes das rodovias, as concentrações de $\mathrm{Cu}$, Zn e $\mathrm{Cr}$ foram maiores que nas distâncias intermediárias, pela relação direta com o índice de matéria orgânica. $\mathrm{O}$ Cd atingiu valores acima dos limites estabelecidos pela Cetesb em pelo menos um subponto do $\mathrm{P}_{1}$ e $\mathrm{P}_{2}$, o que demanda atenção quanto aos efeitos deste metal no meio ambiente. $\mathrm{Cu}$, Co e $\mathrm{Zn}$ superaram o VP em pelo menos um subponto nas duas rodovias. Portanto, monitoramento e ações para mitigar efeitos do tráfego de veículos são importantes para evitar contaminação na região do Córrego da Cascata.

Palavras-chave: Córrego da Cascata, águas pluviais, tráfego de veículos, valores de referência, rodovias urbanas.

ABSTRACT - Due to the flow of vehicles at Domingos Sartori and Marechal Rondon highways (Botucatu-SP) and the possibility of springs contamination near the roads, a study was carried out to monitor metallic species in the region's soil. The objectives of this study were to determine the concentrations of $\mathrm{Cd}, \mathrm{Pb}, \mathrm{Cu}, \mathrm{Co}, \mathrm{Cr}, \mathrm{Ni}, \mathrm{Zn}$ and $\mathrm{Sb}$ in soil samples, verifying their relationship with organic matter, and to identify contamination sources. The determination of the metal species was performed using an atomic emission spectrometer with inductively coupled plasma. The results were evaluated using Tukey test. According to the results, the concentrations were in the range from 1.2 to 11.0 times higher in $\mathrm{P}_{2}$ than in $\mathrm{P}_{1}$. At the nearest sampling points and at the most distant points of the highways, the concentrations of $\mathrm{Cu}, \mathrm{Zn}$ and $\mathrm{Cr}$ were greater than in the intermediate distances and was found a direct relation with the organic matter index. The Cd reached values above the limits established by Cetesb in at least one sub-item of $\mathrm{P}_{1}$ and $\mathrm{P}_{2}$, which requires attention in regarding to its effects over biota and environment. $\mathrm{Cu}$, Co and $\mathrm{Zn}$ outperform PV in at least one sampling sub-point on both highways. Therefore, monitoring and actions to mitigate the effects of vehicular traffic are important to avoid contamination in the Cascata Brook region.

Keywords: Cascata Brook, stormwater runoff, vehicular traffic, reference values, urban road.

\section{INTRODUÇÃO}

A utilização da malha rodoviária é a principal estratégia para a disseminação de produtos e riquezas (Bager \& Fontoura, 2012). Usando combustíveis fósseis, o transporte rodoviário contribui para a mudança da composição físico-química da biosfera, nela introduzindo elementos e compostos químicos que estavam depositados em profundidade na crosta terrestre (DNIT, 2005). Segundo Matos (2011), o produto da combustão do combustível fóssil, enquanto suspenso no ar, pode ser absorvido pelo ecossistema, prejudicando os ciclos biológicos na região.

Para Leitão et al. (2000), a crescente demanda por transporte a combustível fóssil tem aumentado a emissão de gases, prejudicando a atmosfera, o solo, as águas, principalmente próximo às rodovias, onde ocorre também contaminação por desgaste de componentes veiculares e de elementos da infraestrutura 
viária. As águas pluviais urbanas carreadas pelas rodovias também são fontes de poluição e, segundo Kayhanian et al. (2007), contaminam corpos d’água devido ao volume médio diário (VMD) de tráfego, à frequência e à intensidade pluviométrica, ao período de estiagem, ao método de drenagem, ao tipo de pavimento e às áreas de uso de solos (áreas agrícolas).

Segundo Yannopoulos et al. (2013), as primeiras águas de chuva (first flush) em uma rodovia têm potencial de poluição e, por isso, devem ser interceptadas antes de atingir um corpo d'água.

As fontes das espécies metálicas contaminantes podem ser naturais (relacionadas à natureza da rocha que originou o solo e aos agentes geológicos envolvidos na sua formação) ou antropogênicas (relacionadas a efluentes industriais, esgoto doméstico, mineração, dentre outros) (Adriano, 1986).

De acordo com Pinto (2005), certos produtos manufaturados, como fertilizantes, pesticidas, combustíveis fósseis, baterias, aditivos, lubrificantes e catalisadores, podem conter espécies metálicas contaminantes.

O solo natural apresenta constituintes orgânicos, minerais, microrganismos e macrorganismos. Os metais, que não são quimicamente degradados ou biodegradados, tornam-se um problema ambiental. Matos (2011), Duarte (2003) e Adriano (1986) declaram que o solo tem capacidade de reter esses elementos, porém, se essa capacidade for ultrapassada, as espécies metálicas presentes no meio podem penetrar na cadeia alimentar dos organismos ou ser lixiviadas, colocando em risco a qualidade das águas superficiais e subterrâneas.
Para tornar os metais menos biodisponíveis e imobilizados para solo e plantas, é comum a adição de matéria orgânica (MO) e cal, que alcalinizam e, consequentemente, aumentam a capacidade de complexação (Adriano, 1986). O solo e a MO são controladores naturais da biodisponibilidade e mobilidade da maioria das espécies metálicas devido a processos químicos e físicos que desencadeiam, por exemplo, adsorção, complexação e/ou quelação (VinhalFreitas et al., 2010).

Neste estudo foi relevante determinar diferentes pontos de amostragem em áreas adjacentes às rodovias Domingos Sartori e Marechal Rondon, áreas estas vulneráveis a contaminação por espécies metálicas.

Pela Rodovia Domingos Sartori, entre Botucatu e o distrito de Rubião Júnior, próximo ao Câmpus da Universidade Estadual Paulista Júlio de Mesquita Filho (Unesp), trafega o volume diário médio (VDM) de 13.254 veículos, segundo a Concessionária Rodovias do Tietê. A Rodovia Marechal Rondon, a leste da sub-bacia do Córrego da Cascata, escoa a produção do Oeste Paulista, registrando VDM de 18.165 veículos (Concessionária Rodovias do Tietê). Ambas as rodovias podem apresentar focos de contaminação por espécies metálicas devido ao tráfego de veículos, prejudicando a qualidade da água e do solo da região.

Assim, este estudo busca analisar o teor das espécies metálicas $\mathrm{Cd}, \mathrm{Pb}, \mathrm{Cu}, \mathrm{Co}, \mathrm{Cr}, \mathrm{Ni}, \mathrm{Zn}$ e Sb e sua relação com a MO nos cruzamentos do Córrego da Cascata com as Rodovias Domingos Sartori $\left(\mathrm{P}_{1}\right)$ e Marechal Rondon $\left(\mathrm{P}_{2}\right)$ e identificar fontes de contaminação.

\section{CARACTERIZAÇÃO DA ÁREA DE ESTUDO}

O estudo foi realizado na sub-bacia do Córrego da Cascata, na região oeste de BotucatuSP, junto ao Câmpus da Unesp, distrito de Rubião Júnior, nos limites da Estrada de Ferro Sorocabana, ao norte, e do bairro Recanto Azul e da vila São Luiz, a leste, cortada transversalmente pela Rodovia Marechal Rondon e longitudinalmente pela Rodovia Domingos Sartori (Figura 1).

O Córrego da Cascata atravessa longitudinalmente a sub-bacia e tem comprimento principal de 4,76 km da nascente à sua foz, entre propriedades rurais de pequeno porte $\mathrm{e}$ condomínios residenciais. Conta com 13 nascentes: 8 na margem esquerda e 5 na direita.

A montante da Rodovia Domingos Sartori $(\mathrm{km}$ 2), há uma nascente e uma queda-d’água do Córrego da Cascata; e a jusante, um lago defronte ao condomínio Parque das Cascatas e outros tributários, até a foz, na confluência do Córrego Água Fria (Figura 1).

Este, por sua vez, desemboca no Ribeirão Lavapés e atinge a represa de Barra Bonita, no Rio Tietê. Predominam na região os Latossolos e os Argissolos Vermelho-Amarelo Distróficos (LVAd e AVAd). 


\section{Pontos de amostragem}

A coleta das amostras de solo ocorreu em 12 de maio de 2014. Os totais pluviométricos (mm de chuva) nos meses anteriores foram: janeiro: 74,2; fevereiro: 115,8; março: 104,1; abril:
99,1; e maio: 71,8. Nos últimos 20 dias que antecederam a coleta, não houve precipitação pluviométrica $(0,0 \mathrm{~mm})$. Dados obtidos pelo Departamento de Solos e Recursos Ambientais da FCA-Unesp.

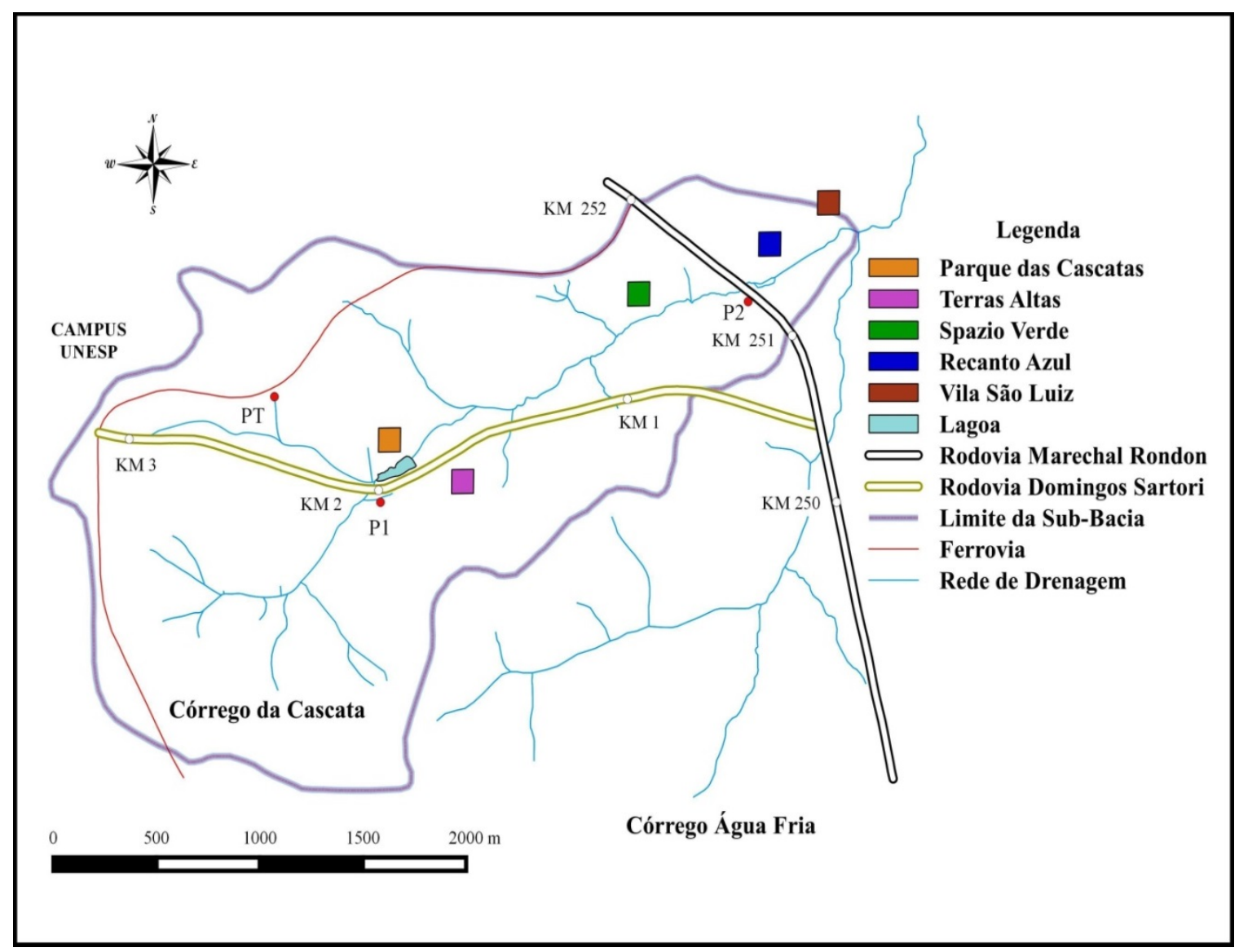

Figura 1 - Localização da sub-bacia do Córrego da Cascata, sua rede de drenagem, pontos de amostragem $\left(\mathrm{P}_{1}, \mathrm{P}_{2}\right.$ e $\left.\mathrm{P}_{\mathrm{T}}\right)$ e seu principal afluente, Córrego Água Fria.

As distâncias entre os pontos de amostragem foram estabelecidas conforme estudos de Markus \& McBratney (2001), segundo os quais os particulados oriundos de poluição atmosférica e desgaste de componentes veiculares normalmente se depositam a uma distância de 15 a 20 metros da rodovia.

Para Adriano (1986), os particulados maiores precipitam rapidamente nos primeiros 5 metros da pista de rolagem, e os menores se depositam lentamente nos primeiros 100 metros.

Assim, o $\mathrm{P}_{1}$, coordenadas $\mathrm{x}=758.535,000$ e $\mathrm{y}=7.466 .118,000$, obtidas pelo Sistema de Projeção UTM, datum WGS 84, zona 22 S, com equipamento GPS (Global Positioning System) da marca Garmin, foi subdividido em 4 subpontos perpendiculares à rodovia e em cada lado da pista de rolagem, distanciados entre si com as seguintes medidas a partir do término lateral da pista de rolagem: $1 \mathrm{~m}, 11 \mathrm{~m}, 26 \mathrm{~m}$ e $41 \mathrm{~m}$. Os subpontos foram identificados a montante como $\mathrm{P}_{1.1}, \mathrm{P}_{1.2}$, $\mathrm{P}_{1,3}$ e $\mathrm{P}_{1.4}$ e a jusante como $\mathrm{P}_{1.5}, \mathrm{P}_{1.6}, \mathrm{P}_{1.7}$ e $\mathrm{P}_{1.8}$ (Figura 2). $\mathrm{O}$ ponto testemunho $\left(\mathrm{P}_{\mathrm{T}}\right)$ foi demarcado em uma das nascentes, sem fluxo de veículos ou outra interferência antrópica, cujas coordenadas foram: $\mathrm{x}=758.082,050$ e $\mathrm{y}=7.466 .551,640$.

Com as mesmas medidas de distância estabelecidas para os subpontos do $\mathrm{P}_{1}$, no $\mathrm{P}_{2}$ as coordenadas foram $\mathrm{x}=760.336,000$ e $\mathrm{y}=7.467 .023,000$, e os subpontos localizados a montante, dispostos perpendicularmente à Rodovia Marechal Rondon, foram identificados como $\mathrm{P}_{2.10}, \mathrm{P}_{2.11}, \mathrm{P}_{2.12}$ e $\mathrm{P}_{2.13}$, e a jusante, como $\mathrm{P}_{2.14}, \mathrm{P}_{2.15}, \mathrm{P}_{2.16}$ e $\mathrm{P}_{2.17}$. Os subpontos $\mathrm{P}_{1.9}$ $(y=759.066,300$ e $x=7.466 .507,460)$ e $P_{2.18}$ $(y=760.725,950$ e $x=7.467 .209,980)$ foram amostrados a uma distância de 620 m e 400 m, respectivamente, das rodovias (Figura 3 ). 


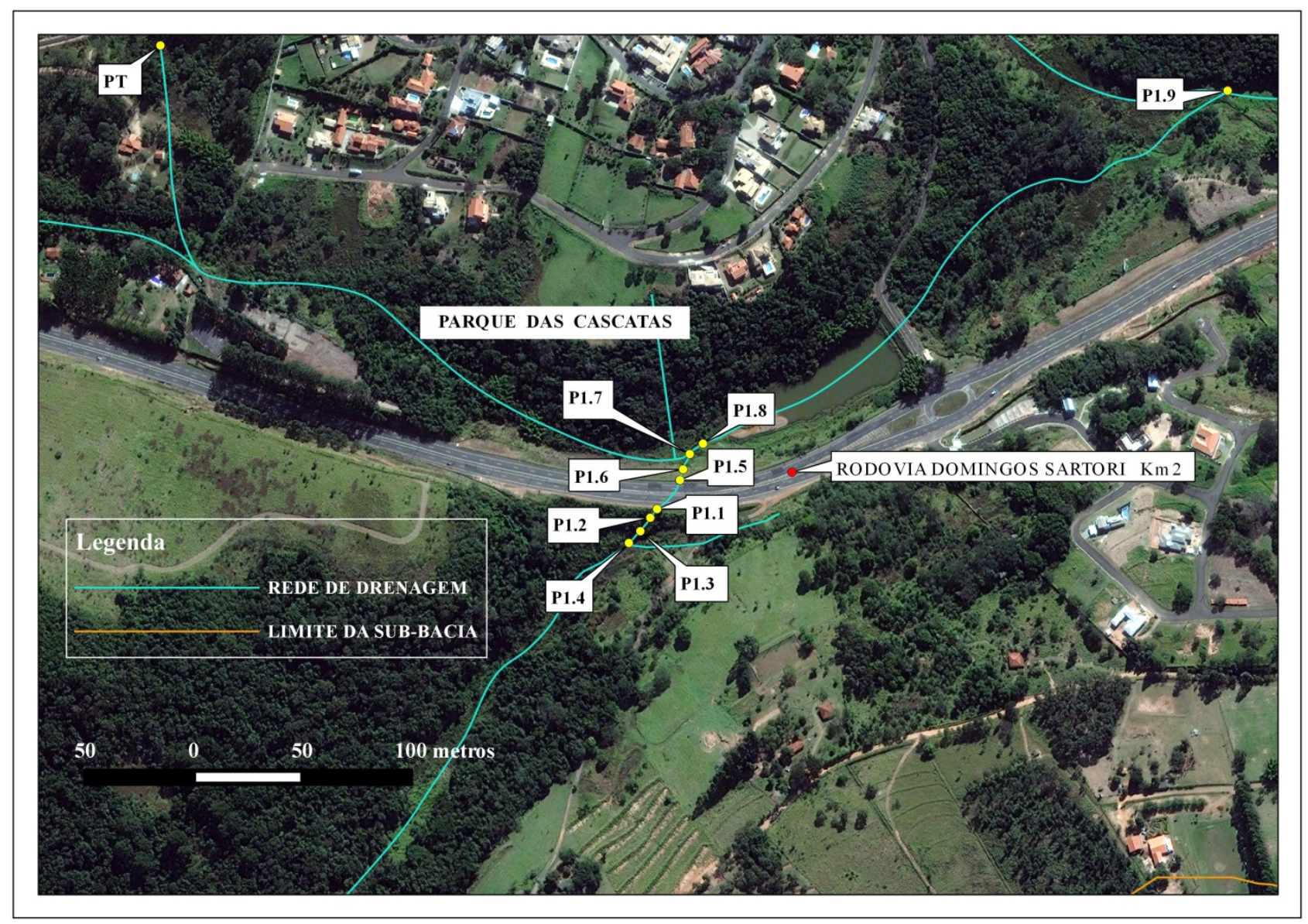

Figura 2 - Localização dos pontos de amostragem nas adjacências da Rodovia Domingos Sartori.

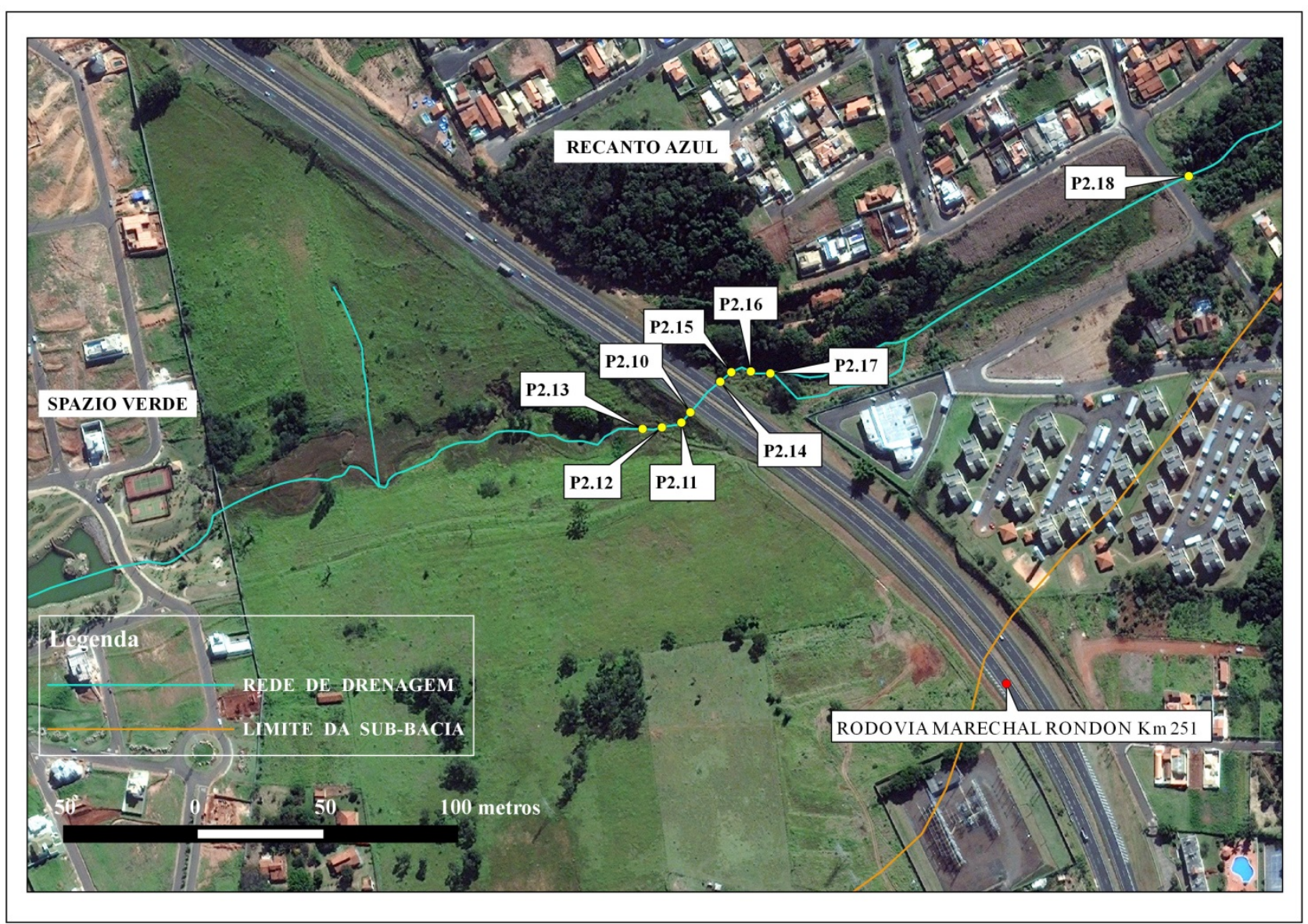

Figura 3 - Localização dos pontos de amostragem nas adjacências da Rodovia Marechal Rondon. 


\section{MATERIAL E MÉTODOS}

\section{Processamento das amostras}

As amostras foram coletadas com um trado de aço inoxidável, em uma camada do solo a 20 cm de profundidade, tendo sido antes removidos detritos da superfície. Foram armazenadas em frascos de polietileno de alta densidade e levadas ao laboratório.

Após mistura e homogeneização das amostras, uma alíquota foi acondicionada em saco plástico para processamento no laboratório do Departamento de Química do Instituto de Biociências da Unesp Botucatu. Dessas amostras, 19 foram secas em estufa com circulação de ar a $80{ }^{\circ} \mathrm{C}$, fracionadas e homogeneizadas, tendo fração inferior a $75 \mu \mathrm{m}$ de abertura submetida a mineralização. Em geral, frações inferiores a $75 \mu \mathrm{m}$ apresentam alto teor de metais, cujas áreas superficiais são elevadas e carregadas eletricamente, favorecendo ligações entre as espécies metálicas e outros contaminantes, sendo consideradas indicadores sensíveis de poluição. Em uma avaliação granulométrica, Pinto (2005) e Minello et al. (2009) mostraram que a fração inferior a $63 \mu \mathrm{m}$ está associada à MO, já que o teor de metal também aumenta à medida que o tamanho do grão diminui, processo esse governado pela adsorção.

\section{Processamento, mineralização e leitura das amostras}

Com uma balança analítica, pesou-se em triplicata $1,0 \mathrm{~g}$ de amostra de solo, que foram digeridas em solução ácida nitroclorídrica, na proporção 1:3 (Água Régia), adaptado de Keller \& Védy (1994). Foram adicionados $3 \mathrm{ml}$ de $\mathrm{HNO}_{3}$ concentrado (Merck) a cada alíquota, deixando-se o sistema em repouso por 12 horas. A seguir, foram adicionados $9 \mathrm{ml}$ de $\mathrm{HCl}$ concentrado (J. T. Baker), deixando-se o sistema à temperatura de $100^{\circ}$ a $110{ }^{\circ} \mathrm{C}$, em bloco digestor em digestão aberta, por 2 horas. Depois, adicionou-se $1 \mathrm{ml}$ de peróxido de hidrogênio a quente, deixando-se o sistema por mais 30 minutos no bloco digestor. $\mathrm{O}$ material foi transferido quantitativamente para balão volumétrico de $25 \mathrm{ml}$, com uso de água ultrapura e, depois, para frascos de polietileno identificados, sendo armazenado em geladeira para análise. Segundo Minello et al. (2009), a digestão aberta é tão eficiente e confiável quanto os outros dois métodos quando se trata de analitos não voláteis (USEPA - 3050B). Não houve perdas dos analitos pelo efeito de arraste de vapor.

Para evitar contaminação cruzada, toda a vidraria utilizada no processamento das amostras foi descontaminada por banho de imersão em solução de $\mathrm{HNO}_{3}$ a $10 \%$ durante 24 horas. As amostras foram encaminhadas ao Departamento de Solos e Recursos Ambientais da FCA-Unesp.

Para garantir a qualidade analítica, foram utilizadas referências certificadas dos elementos estudados da marca Quimlab Produtos de Química Fina Ltda rastreados pelo National Institute of Standard and Tecnology (NIST). As espécies metálicas foram determinadas conforme configurações descritas no manual do fabricante Perkin Elmer modelo Optima 8300. Para averiguar a exatidão do equipamento, a cada 10 leituras das amostras fazia-se uma leitura de um padrão de concentração intermediária (em relação à curva analítica).

\section{Índice de matéria orgânica}

Cerca de 1,0 g de amostra de solo foi peneirado, pesado e transferido para uma cápsula de porcelana. O carbono orgânico da amostra foi determinado pela diferença de massa antes e após a calcinação em mufla à temperatura de $550{ }^{\circ} \mathrm{C}$ durante 4 horas (COTTA, 2003).

\section{Background geoquímico e valores orientadores para solos}

Background geoquímico é a diferença entre as medidas das concentrações naturais de um dado elemento e as concentrações de origem antrópica (Rodrigues \& Nalini Júnior, 2009).

Os valores background obtidos nos estados de São Paulo e Paraná são bem próximos. Optou-se então por utilizar o Atlas Geoquímico da Bacia do Paraná (Mineropar, 2001) e o Atlas da Bacia do Vale do Ribeira (Lopes Júnior, 2007), que apresentam valores gerados a partir da fração inferior a $80 \mu \mathrm{m}$, próximo a $75 \mu \mathrm{m}$, utilizado neste estudo. Outros valores orientadores, restritos aos solos de São Paulo, foram adaptados pela Cetesb (2014). O valor de referência de qualidade (VRQ) é a concentração de determinada substância pela qual se define um solo limpo; o valor de prevenção (VP) é a concentração acima da qual podem ocorrer alterações 
prejudiciais à qualidade do solo, e o valor de intervenção agrícola (VI) são os riscos potenciais à saúde humana.

\section{Tratamento estatístico}

O comportamento das variáveis nos diversos locais foi checado por análise de variância seguida do teste de Tukey (Tukey’s Studentized Range-HSD), no nível de 5\% de significância, para comparação das médias. Foi elaborado um gráfico de médias e desvios-padrão (Sokal \& Rohlf, 1995) com a simetria e a dispersão dos dados das variáveis estudadas.

\section{RESULTADOS E DISCUSSÃO}

As espécies metálicas analisadas no presente estudo foram selecionadas em razão de sua origem antrópica (em rodovias).

Devido ao alto volume médio diário (VMD) de tráfego e ao desgaste dos componentes veiculares, particulados suspensos no ar precipitam-se sobre as rodovias. A água de escoamento das chuvas (rainfall-runoff) transporta esses resíduos para áreas próximas das rodovias e para partes baixas da sub-bacia até os corpos d'água. Dos metais analisados, apenas o Sb teve resultados inferiores ao limite de detecção da técnica empregada $\left(<1,0 \quad\right.$ mg.kg $\left.{ }^{-1}\right)$. As concentrações médias das espécies metálicas analisadas revelam que a Rodovia Marechal Rondon $\left(\mathrm{P}_{2}\right)$ é mais contaminada que a Domingos Sartori $\left(\mathrm{P}_{1}\right)$ (Figura 4). No box-plot, a maior variação, assimetria e amplitude (dispersão) das concentrações para os elementos $\mathrm{Cu}$ e $\mathrm{Zn}$, além dos valores atípicos (“*”outlier). Calculando a razão $\mathrm{P}_{2} / \mathrm{P}_{1}$ das concentrações médias de cada metal nos respectivos subpontos, foi encontrada a variação de 1,2 a 11,0 vezes mais concentrado para o $\mathrm{P}_{2}$.

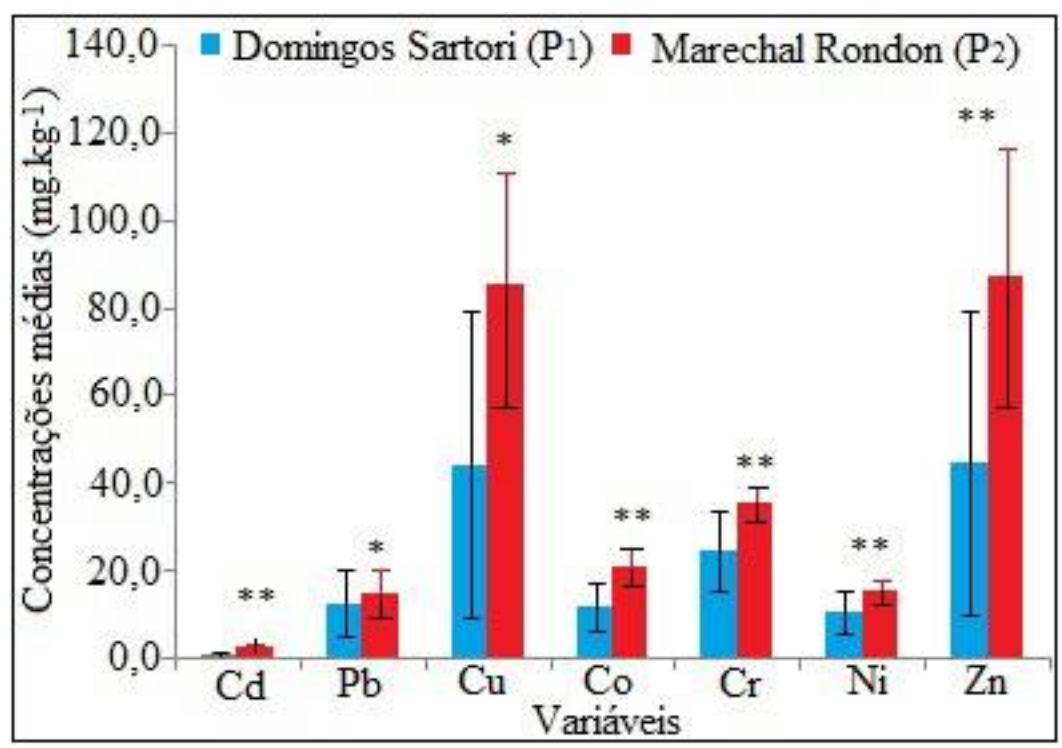

Figura 4 - Relações entre as concentrações médias e desvios padrão de cada metal nas rodovias $*(p<0,05) * *(p<0,001)$.

As diferenças de concentração das espécies metálicas entre as rodovias podem decorrer do fato de ser a rodovia Marechal Rondon mais antiga (desde 1954), acumulando mais metais no solo, além de apresentar um VMD de tráfego superior (18.165 veículos) em relação ao $\mathrm{P}_{1}$ (13.234 veículos), o que corresponde a 1,4 vezes maior. Também se observou que o $\mathrm{P}_{2}$ apresenta tráfego intenso de veículos leves e pesados, enquanto no $\mathrm{P}_{1}$ há tráfego de veículos leves e poucos ônibus.

Em seus estudos, Duarte \& Pasqual (2000), Duarte (2003), Beló et al. (2010), Martinez (2010), Figueiredo (2011) e Santos et al. (2013) encontraram correlação entre a acumulação e a dispersão de elementos metálicos e o VMD de tráfego, o que coincide com estudos feitos em outras cidades do mundo.

Assim, o tráfego de veículos tem efeito impactante na qualidade das águas de escoamento das chuvas até os corpos d'água (Kayhanian et al., 2007)).

As associações entre as espécies metálicas e os componentes do solo parecem fundamentais para o seu comportamento. Comparando as concentrações dos metais e o índice de matéria orgânica (IMO) em $\mathrm{P}_{1}$ e $\mathrm{P}_{2}$, foram obtidas as concentrações médias para cada espécie em cada subponto (Figura 5). 


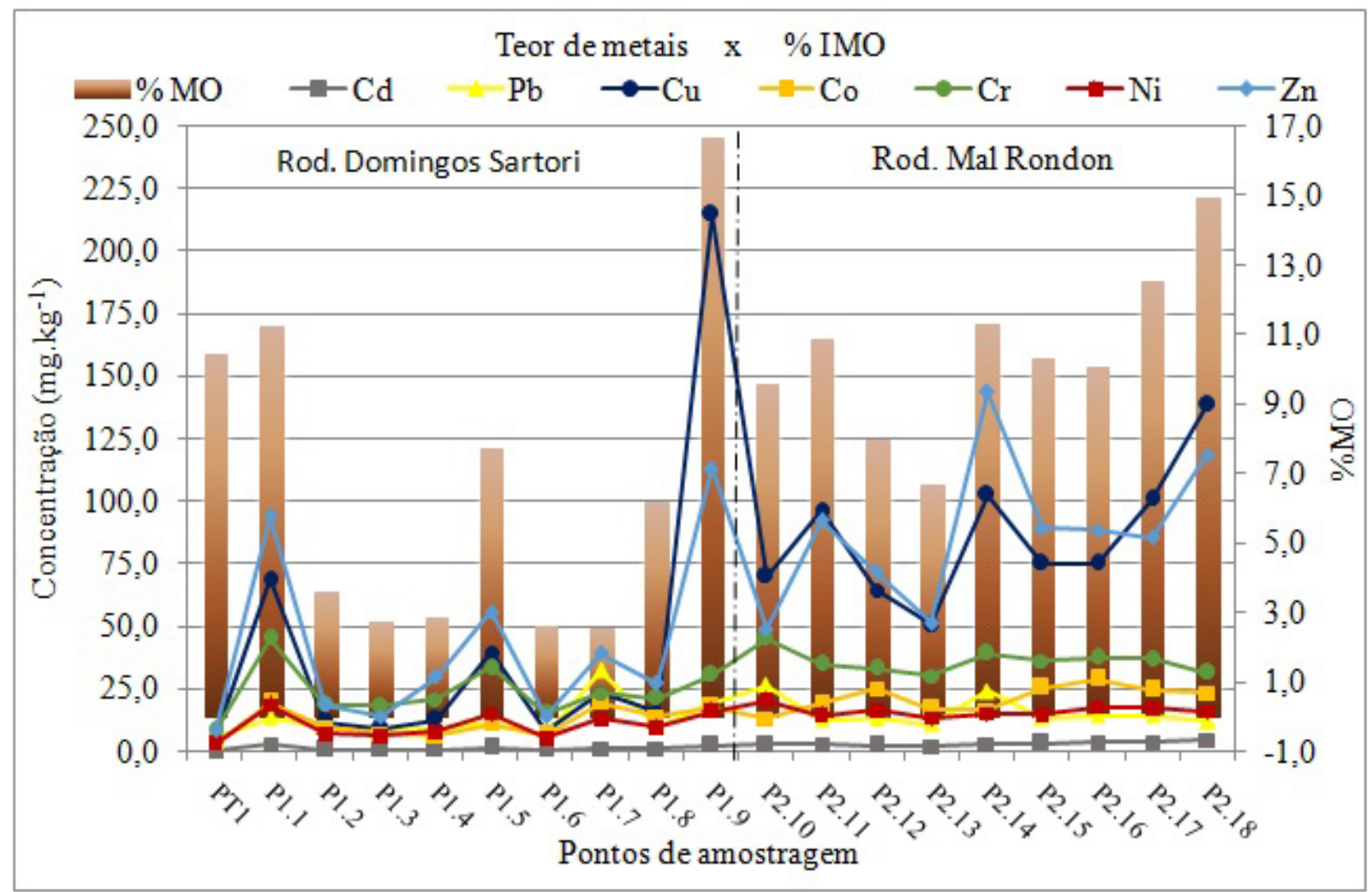

Figura 5- Variação das concentrações de solos nos pontos de amostragem $\left(\mathrm{P}_{1}\right.$ e $\left.\mathrm{P}_{2}\right)$. À direita, escala do IMO (\%) e, à esquerda, das espécies metálicas obtidos em mg. $\mathrm{kg}^{-1}$.

A interação de diversos fatores afeta a mobilidade e a disponibilidade dos metais: $\mathrm{pH}$, CTC (capacidade de troca iônica) e teores de argila, silte, Fe, Mn (Adriano, 1986, Duarte, 2003, Leitão et al., 2000, Broska et al., 2010). Neste estudo foi avaliada apenas a interação química entre a MO e as espécies metálicas da camada superficial do solo.

Os teores do ponto testemunho $\left(\mathrm{P}_{\mathrm{T}}\right)$ dos metais em solos estão inferiores aos valores encontrados para a maioria dos subpontos e não têm relação direta com o elevado IMO (10,4\%). O P 1.9 apresenta-se com IMO maior (16,6\%) e segue em ordem decrescente de concentração $\mathrm{P}_{1.1} \quad(11,2 \%), \quad \mathrm{P}_{1.5} \quad(7,7 \%)$ e $\mathrm{P}_{1.8} \quad(6,2 \%)$, mantendo relação direta com a $\mathrm{MO}$ principalmente para os metais $\mathrm{Cu}>\mathrm{Zn}>\mathrm{Cr}$. No $\mathrm{P}_{2}$, os mesmos metais seguem a mesma ordem $\left(\mathrm{Cu}>\mathrm{Zn}>\mathrm{Cr}\right.$ ), iniciando no $\mathrm{P}_{2.18}$ com o maior IMO (14,9\%), seguido do $\mathrm{P}_{2.17}(12,5 \%), \mathrm{P}_{2.14}$ (11,3\%), $\mathrm{P}_{2.15}(10,3 \%)$ até $\mathrm{P}_{2.13}(6,54 \%)$. Os demais subpontos apresentam baixo IMO, e os outros metais não têm relação com a MO.

De acordo com Kabata-Pendias (2010), a MO e os complexos ou quelatos metaloorgânicos do solo são importantes na lixiviação e na acumulação de cátions metálicos para a estabilidade e o fornecimento destes íons às raízes das plantas. Segundo Adriano (1986), a MO correlacionada às trocas iônicas e compostos do solo (óxidos) para a maioria dos metais interfere na absorção destes pelas plantas.

Observa-se que os teores de metais no $\mathrm{P}_{1}$ $\left(\mathrm{P}_{1.1}, \mathrm{P}_{1.5}\right)$ e no $\mathrm{P}_{2}\left(\mathrm{P}_{2.10}\right.$ e $\left.\mathrm{P}_{2.14}\right)$ são elevados devido à proximidade das rodovias dos demais subpontos de amostragem (Figuras 2, 3 e 5), resultados estes similares aos estudos de Duarte (2003), Leitão et al. (2000) e Broska et al. (2010).

Apesar do risco de contaminação cruzada por metais devido ao aterramento na duplicação da Marechal Rondon (1997) e da Domingos Sartori (2004), acredita-se que não houve interferência nos resultados obtidos nesses solos de empréstimo. Conforme a DNIT (2006), em áreas de aterros, os solos originais de baixa resistência e inaptos a qualquer uso, geralmente de origem orgânica, são removidos da rodovia e substituídos por solos de terrenos naturais (saibros) antes da pavimentação.

Nos subpontos de amostragem observados, o $\mathrm{P}_{1}\left(\mathrm{P}_{1.2}\right.$ a $\mathrm{P}_{1.4}$ e $\mathrm{P}_{1.6}$ a $\left.\mathrm{P}_{18}\right)$ e o $\mathrm{P}_{2}\left(\mathrm{P}_{2.11}\right.$ e $\mathrm{P}_{2.13}$ e $\mathrm{P}_{2.15}$ e $\mathrm{P}_{2.17}$ ) apresentaram concentrações menores e, em alguns pontos, a redução foi inversamente proporcional à distância da 
rodovia. Duarte (2003) e Silva et al. (2013) observaram resultados similares, com aumento da concentração de metais nos solos correlacionado ao inverso da distância das rodovias.

O subponto $\mathrm{P}_{1.9}$ fica a aproximadamente 620 $\mathrm{m}$ da rodovia $\left(\mathrm{P}_{1}\right)$, a jusante do condomínio Parque das Cascatas e na confluência de um tributário do córrego principal da sub-bacia (Figura 2). Nesse subponto, o alto teor de $\mathrm{Cu}$ e $\mathrm{Zn}$, entre outros metais, pode ter origem nas águas de chuva tanto do condomínio como do estacionamento desativado de vagões e trens da antiga linha férrea, situado na linha do divisor de águas da sub-bacia. Nos outros tributários apresentados na mesma figura não foi constatada possível contaminação secundária.

$\mathrm{O} \quad \mathrm{P}_{2.18}, \quad$ localizado também a aproximadamente $400 \mathrm{~m}$ da rodovia $\left(\mathrm{P}_{2}\right)$, apresentou altos teores dos mesmos metais, e a principal suspeita de contaminação difusa foi no bairro Recanto Azul, possivelmente carreada pelas águas de chuva.

A alta concentração de metais nesses subpontos exige um estudo para identificação e quantificação dos elementos contaminantes.

Estudos realizados em Los Angeles, nos Estados Unidos (Kayhanian et al., 2008), e Guanzhou, na China (Gan et al., 2008) registraram altos índices de contaminação por $\mathrm{Cu}$ e Zn em amostras de água coletadas em eventos de chuva após períodos de estiagem.

Neste estudo, embora a precipitação pluviométrica em maio/2014 tenha sido inferior em relação aos meses anteriores, e nos últimos 20 dias antes da coleta não tenha ocorrido precipitação, pode-se inferir que esse período não foi influenciado por first flush. Assim, os teores de espécies metálicas apresentados vêm se acumulando nas rodovias por influência do tráfego desde a sua construção.

Para avaliar o grau de contaminação por metal no solo, o mapa geoquímico com enfoque geoambiental de valores de referência ou background geoquímico é uma ferramenta importante. Conforme o Atlas Geoquímico da Bacia do Paraná (Mineropar, 2001), a composição de uma amostra de água ou de sedimento de fundo de um canal de drenagem reflete a soma das características químicas dos materiais que ocorrem na bacia hidrográfica, podendo revelar a atuação de fontes naturais ou antrópicas.

A contaminação do solo por Cd, especificamente, revela seu grande potencial ecotóxico (Kabata-Pendias, 2010). Na natureza, o Cd raramente ocorre em forma pura e é restrito à camada superficial dos solos ricos em MO. Sua mobilidade e fitodisponibilidade dependem das propriedades químicas dos solos e não da sua capacidade quelante (Adriano, 1986, Kabata-Pendias, 2010).

De acordo com a Mineropar (2001), a concentração média natural para solos estabelece limite máximo de $0,11 \mathrm{mg} \cdot \mathrm{kg}^{-1}$ para o Cd; no entanto esse metal, nos subpontos do $P_{1}$, variou entre 2,0 a 22,0 vezes, e no $P_{2}$, variou de 16,0 a 40,0 vezes esse limite. Isso demonstra que a Rodovia Marechal Rondon sofreu maior influência do VMD de tráfego para o Cd em relação à Domingos Sartori.

As faixas de valores utilizadas como parâmetros de qualidade de solo para os metais aqui estudados podem ser observadas nas Figuras 5 e 6.

De acordo com a Cetesb (2014), o VRQ, os limites máximos do metal $\mathrm{Cd}$ foram superados (0,5 mg.kg $\left.{ }^{-1}\right)$ no $\mathrm{P}_{1}\left(\mathrm{P}_{1.7}\right.$ e $\left.\mathrm{P}_{1.8}\right)$ e tendendo ao VP (1,3 mg. $\left.\mathrm{kg}^{-1}\right)$ e, acima deste, os valores médios do $\mathrm{P}_{1.1}, \mathrm{P}_{1.5}$ e $\mathrm{P}_{1.9}$ excedem o limite do VP (Figura 6A). O valor do Cd, superior a 3,6 mg. $\mathrm{kg}^{-1}$, condiz com os valores limites de VI e ocorre somente no $\mathrm{P}_{2.18}$. As concentrações próximas do VI no $\mathrm{P}_{2.16}\left(3,37 \mathrm{mg} \cdot \mathrm{kg}^{-1}\right)$ e $\mathrm{P}_{2.17}\left(3,47 \mathrm{mg} \cdot \mathrm{kg}^{-1}\right)$ para o mesmo metal indicam um alerta no $\mathrm{P}_{1} \mathrm{e}$ devem ser monitoradas periodicamente.

$\mathrm{O} \mathrm{Pb}$ não é essencial na nutrição e não ocorre em abundância na natureza. Se de origem antropogênica, é perigoso por ser absorvido pelas plantas e ter efeito cumulativo nos organismos, provocando doenças (Mineropar, 2001).

A MO presente no solo forma complexos quelatos e outros constituintes (óxidos, carbonatos, argila, silte etc.) do solo, o que provoca interferência na captação ou absorção de $\mathrm{Pb}$ pelas plantas (Adriano, 1986). Entre as espécies metálicas do solo, o Pb é a menos móvel, embora sua sorção seja inferior à do $\mathrm{Cu}$ e do Zn. Apresenta também alta propriedade calcofílica e, por isso, quando isolado ou combinado com outras espécies metálicas, forma compostos sulfetados, como a galena (PbS) (Kabata-Pendias, 2010). 

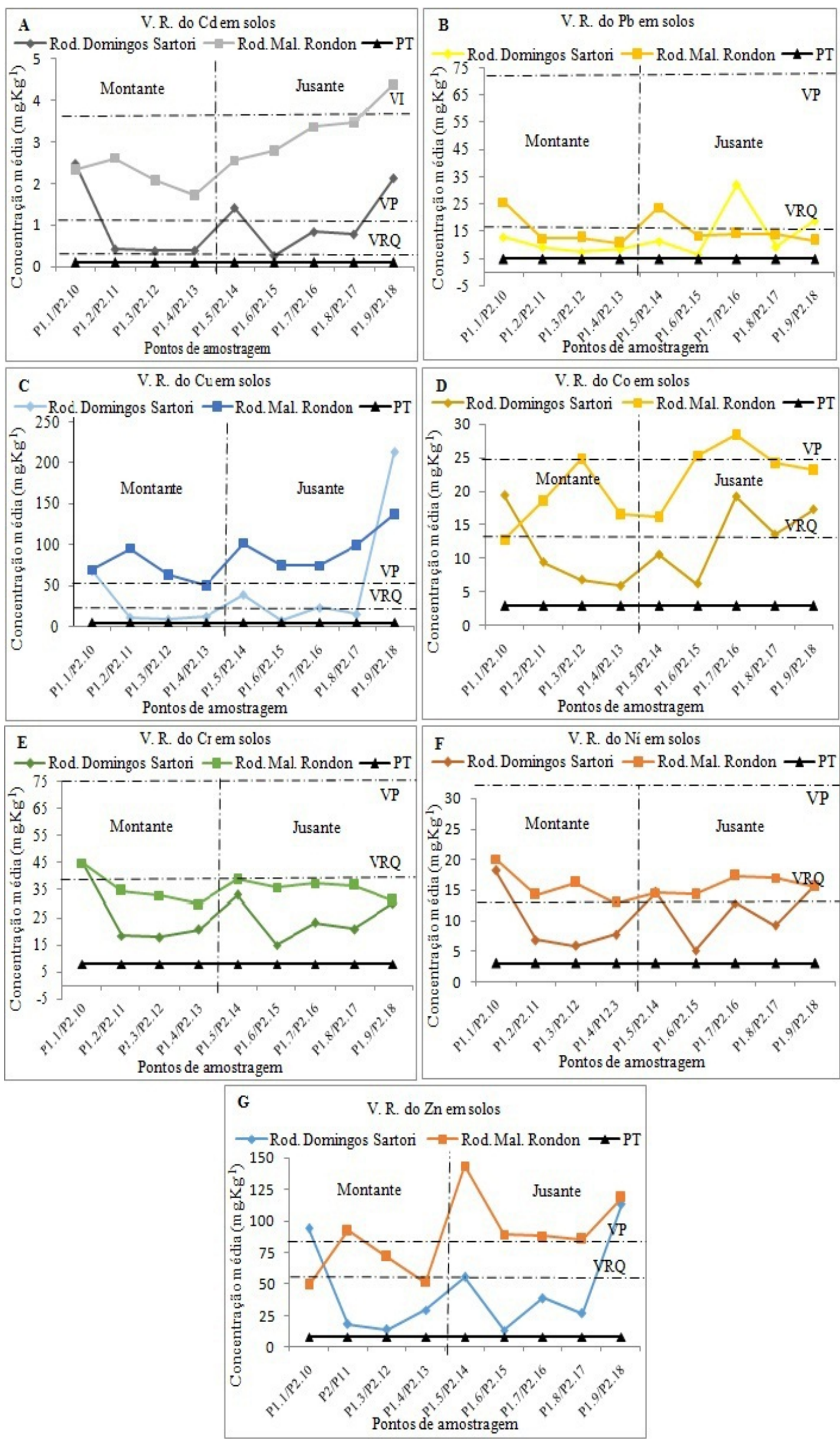

Figura 6 - Variação das concentrações de cada espécie metálica em solos nos pontos de amostragem segundo os valores orientadores VRQ e VP. 
A Figura 6B apresenta as concentrações médias de $\mathrm{Pb}$ nas duas rodovias, sendo, no $\mathrm{P}_{1}$, o $\mathrm{P}_{1.7}\left(32,0 \mathrm{mg} \cdot \mathrm{kg}^{-1}\right)$ e o $\mathrm{P}_{1.9}\left(18,9 \mathrm{mg} \cdot \mathrm{kg}^{-1}\right)$ acima do limite do VRQ (17,0 mg.kg-1) e do limite background $\left(<18,59 \mathrm{mg} \cdot \mathrm{kg}^{-1}\right)$. Os subpontos $\mathrm{P}_{2.10}\left(25,9 \mathrm{mg} \cdot \mathrm{kg}^{-1}\right)$ e $\mathrm{P}_{2.14}\left(23,8 \mathrm{mg} \cdot \mathrm{kg}^{-1}\right)$ do $\mathrm{P}_{2}$ apresentam valores mais próximos do VRQ em relação ao VP (72,0 mg. $\mathrm{kg}^{-1}$ ) e pouco acima dos níveis naturais. O VI para esse elemento deverá ser superior a 150,0 mg. $\mathrm{kg}^{-1}$, não havendo necessidade de monitoramento e controle por estar em nível bem inferior.

Broska et al. (2010) avaliaram o $\mathrm{Pb}$ às margens da BR 116 e da BR 277, na região de intenso tráfego entre Curitiba e São José dos Pinhais, no Paraná. Verificaram incremento do metal 10 vezes maior no local onde ocorria escoamento de águas da chuva na pista em relação a outros pontos em que não havia indício de contaminação.

Silva et al. (2013) encontraram elevadas concentrações de $\mathrm{Pb}$, de 23,6 a 27,1 mg.kg-1, à distância máxima de $10 \mathrm{~m}$ da BR 116, região de Caçapava-SP. Esses teores foram superiores aos relatados por Duarte \& Pasqual (2000), que encontraram teores inferiores a $8,9 \mathrm{mg} \cdot \mathrm{kg}^{-1}$ nas quatro rodovias estudadas no centro-oeste do estado de São Paulo, e inferior aos resultados obtidos neste estudo.

$\mathrm{Cu}$, Co e Zn são essenciais para o organismo humano, mas em doses elevadas podem ser tóxicos.

$\mathrm{O}$ metal $\mathrm{Cu}$ apresenta baixa mobilidade e quantidade em relação a outros metais nos solos, pois exige grande habilidade à interação química entre os minerais, componentes orgânicos e pH (Kabata-Pendias, 2010). De acordo com Adriano (1986) e Kabata-Pendias (2010), entre os outros constituintes do perfil superficial do solo (carbonatos, minerais, hidróxidos e outros), a MO revela maior capacidade de sorção com o $\mathrm{Cu}$. Nos perfis de solos pobres em MO e elevadas concentrações desse elemento, pode ocorrer considerável lixiviação e refletir sua bioacumulação, bem como suas fontes antropogênicas.

Para Adriano (1986), os complexos orgânicos envolvendo $\mathrm{Cu}$ e $\mathrm{Pb}$ são consideravelmente estáveis em relação ao Cd, e seguem a ordem $\mathrm{Cu}>\mathrm{Pb}>\mathrm{Cd}$. Os teores obtidos anteriormente entre o $\mathrm{Cu}$ e $\mathrm{MO}$ demonstram forte interação entre o $\mathrm{Zn}$ e o $\mathrm{Cr}(\mathrm{Cu}>\mathrm{Zn}>\mathrm{Cr})$.
Assim como o $\mathrm{Pb}$, o $\mathrm{Cu}$ forma grandes quantidades de minerais sulfetados (calcopirita$\mathrm{CuFeS}_{2}$ e outros), sozinho ou com outros elementos do solo, além de formar hidróxidos e carbonatos, em condições oxidantes (Mineropar, 2005; Kabata-Pendias, 2010).

A Figura 6C mostra que o teor de $\mathrm{Cu}$ no $\mathrm{P}_{1.1}$ (68,3 mg.kg-1) e no $\mathrm{P}_{1.9}\left(214,0 \mathrm{mg} \cdot \mathrm{kg}^{-1}\right)$ está acima do VP, cujo limite é de $60,0 \mathrm{mg} \cdot \mathrm{kg}^{-1}$, e acima do limite background (27,0 mg. $\mathrm{kg}^{-1}$ ), inclusive para o $\mathrm{P}_{1.5}$ (39,3 $\left.\mathrm{mg} \mathrm{kg}^{-1}\right)$ com, respectivamente 2,5, 8,0 e 1,5 vezes superior aos limites naturais. Embora o $\mathrm{P}_{1.9}$ apresente alta concentração acima do VP em relação aos outros subpontos, está distante do limite do VI, que é de 760,0 mg. $\mathrm{kg}^{-1}$. No $\mathrm{P}_{2}$, com exceção do $\mathrm{P}_{2.13}$ (50,4 mg. $\mathrm{kg}^{-1}$ ), os demais apresentaram concentrações médias inferior ao VP e, nos outros subpontos, foram superiores, mas estão também distantes do VI.

Quanto aos limites naturais no $\mathrm{P}_{2}$, todos os subpontos estavam acima e variaram de 2 a 5 vezes maior. Conforme Kabata-Pendias (2010), a concentração inferior a $10,0 \mathrm{mg} \cdot \mathrm{kg}^{-1}$ pode indicar deficiência desse elemento na superfície do solo, o que não é o caso em relação à maioria dos resultados aqui presentes.

O Co não é essencial para plantas, mas seu teor nas gramíneas é preocupante quanto à nutrição animal. A diminuição desse elemento causa deficiência da vitamina $\mathrm{B}_{12}$ (cobalamina), sintetizada pelas bactérias do rumem dos herbívoros, e é elemento essencial, mas em níveis elevados pode causar efeitos deletérios. Esse elemento não é relativamente tóxico para o animal e o homem, mas sua deficiência é preocupação maior que o nível tóxico em plantas (Adriano, 1986).

A mobilidade do Co relaciona-se à presença e ao tipo de MO. Quelatos orgânicos com o Co são facilmente móveis e translocados em solos. Nos solos úmidos, o Co é associado aos carbonatos, MO, enxofre e resíduos e outros autores referem antagonismos entre o Co e o $\mathrm{Ni}$, o $\mathrm{Cu}$, o $\mathrm{Zn}$, entre outros elementos.

No $\mathrm{P}_{1}$, a Figura $6 \mathrm{D}$ apresenta o metal Co acima do limite do VRQ, que equivale a 13,0 mg.kg-1 nos subpontos $\mathrm{P}_{1.1}\left(19,4\right.$ mg. $\left.\mathrm{kg}^{-1}\right), \mathrm{P}_{1.7}$ (19,2 mg. $\left.\mathrm{kg}^{-1}\right)$ e $\mathrm{P}_{1.9}\left(17,3 \mathrm{mg} \cdot \mathrm{kg}^{-1}\right)$, que tendem ao limite do VP (25,0 mg. $\left.\mathrm{kg}^{-1}\right)$, o que sugere necessidade de monitoramento dos seus níveis de prevenção do solo. Os outros 
subpontos estão na faixa do VRQ nessa rodovia. Para o limite natural do Co $(<19$ mg. $\left.\mathrm{kg}^{-1}\right)$, os subpontos $\left(\mathrm{P}_{1.1}, \mathrm{P}_{1.7}, \mathrm{P}_{2.12}, \mathrm{P}_{2.15}\right.$, $\mathrm{P}_{2.16}, \mathrm{P}_{2.17}$ e $\mathrm{P}_{2.18}$ ) estão pouco acima. No $\mathrm{P}_{2}$, somente o $\mathrm{P}_{.2 .10}\left(12,8 \mathrm{mg} . \mathrm{kg}^{-1}\right)$ está na faixa do VRQ e o $\mathrm{P}_{2.16}\left(28,5 \mathrm{mg} \cdot \mathrm{kg}^{-1}\right)$ aproxima-se do limite do VI (35,0 mg. $\left.\mathrm{kg}^{-1}\right)$. Já os outros pontos tendem ao limite do VP, causando preocupação junto aos limites de prevenção.

$\mathrm{O}$ metal $\mathrm{Cr}$ é encontrado no meio ambiente sob a forma trivalente (III), relativamente benigna, e a forma hexavalente (VI), tóxica para o organismo humano. O $\mathrm{Cr}$ III é ligeiramente móvel apenas em meio muito ácido, e o pH 5,5 é quase completamente precipitado, cujos estados de oxidação altamente variáveis permitem a formação de complexos aniônicos e catiônicos $\left(\mathrm{CrOH}^{+2}\right.$, $\left.\mathrm{CrO}_{4}^{+2}, \mathrm{HCrO}_{4}^{-}, \mathrm{HCrO}_{3}{ }^{-2}, \mathrm{Cr}(\mathrm{OH})_{4}^{-}\right)$, e inerte para $\mathrm{Cr}\left(\mathrm{H}_{2} \mathrm{O}\right)^{3+}{ }_{6}$. Espécies, bem como complexos orgânicos, são considerados muito estáveis nos solos.

Por outro lado, Cr VI é muito instável nos solos e facilmente mobilizado em solos ácidos e alcalinos (Kabata-Pendias, 2010). A MO e o Fe II, comumente presentes nos solos orgânicos, podem servir como doadores de elétrons. Assim, a redução pode ocorrer em solos com baixo IMO ou solúvel em Fe II. Se o Fe II está presente, o Cr VI pode ser reduzido, na qual tenderá à imobilização como um hidróxido (Adriano, 1986; Mineropar, 2005; Hooda, 2010).

A Figura 6E apresenta o Cr pouco acima do limite do VRQ (40,0 mg. $\mathrm{kg}^{-1}$ ) com o mesmo valor nos subpontos $\mathrm{P}_{1.1}$ e $\mathrm{P}_{2.10}\left(45,0 \mathrm{mg} \cdot \mathrm{kg}^{-1}\right)$, mas valores abaixo do VP $\left(75,0 \mathrm{mg} \cdot \mathrm{kg}^{-1}\right)$ e de VI que é de 150,0 mg. $\mathrm{kg}^{-1}$. Os demais subpontos estão na faixa do VRQ. O valor background para este elemento é de 62.25 mg. $\mathrm{kg}^{-1}$ e não superou as concentrações obtidas nas duas rodovias.

De acordo com Adriano (1986), Mineropar, 2005 e Kabata-Pendias (2010), o Ni tende a acumular-se na camada orgânica dos solos. Esse elemento é considerado siderófilo se associado ao Fe, e também calcofílico, formando complexos sulfetados. A sorção do $\mathrm{Ni}$ pode ocorrer em formas iônicas e complexadas em ligantes orgânicos e inorgânicos, considerando fatores como MO, $\mathrm{pH}$, textura do solo, índice de carbonatos, sesquióxidos, agentes quelantes e outros. Em geral, as diferenças na sorção e na mobilidade desses metais podem ter origem nas diferenças das propriedades químicas dos solos.

$\mathrm{O} \mathrm{Ni}$ apresentado na Figura 6F, com concentração pouco acima do limite do VRQ (13,0 mg. $\left.\mathrm{kg}^{-1}\right)$ ocorre somente nos subpontos $\mathrm{P}_{1.1}$ (18,2 mg. $\left.\mathrm{kg}^{-1}\right), \mathrm{P}_{1.5}\left(14,7 \mathrm{mg} \cdot \mathrm{kg}^{-1}\right)$ e $\mathrm{P}_{1.9}$ (15,9 mg. $\left.\mathrm{kg}^{-1}\right)$ em relação aos demais na faixa do VRQ no $P_{1}$. No $P_{2}$, com exceção do $P_{2.13}$ (12,9 mg. $\left.\mathrm{kg}^{-1}\right)$, que está na faixa do VRQ, os outros subpontos tendem ao limite do VP (30,0 mg. $\mathrm{kg}^{-1}$ ) para o $\mathrm{Ni}$, mas estão distantes do VI, que é de 190,0 mg. $\mathrm{kg}^{-1}$. O limite natural estabelece limite inferior a 21,01 mg.kg ${ }^{-1}$, o que caracteriza valor acima do VRQ devido à característica química do solo, mas as concentrações nas duas rodovias estão abaixo.

A capacidade de quelação do Ni pela MO é de aproximadamente 2,2\% do seu peso, ou seja, o solo com $1 \%$ de MO poderia complexar no mínimo 220 mg. $\mathrm{kg}^{-1}$ (Adriano, 1986). Se fizermos essa relação com a MO obtidas no $\mathrm{P}_{1}$ e $\mathrm{P}_{2},(16,6 \%$ e $14,9 \%)$, a capacidade de quelação do $\mathrm{Ni}$, estaria acima de 16 e 14 vezes superior, respectivamente, o valor complexante, ou seja, o presente solo deve apresentar alto nível desse metal indisponível. Para Adriano (1986), entre as espécies metálicas, o Cu parece ser o maior inibidor competitivo na captação do $\mathrm{Ni}$ em relação ao Zn, porém foi observado que a adsorção dos metais estava na ordem $\mathrm{Pb}>\mathrm{Cu}>\mathrm{Zn}>\mathrm{Ni}$, e a mobilidade, $\mathrm{Cd}>\mathrm{Ni}>$ $\mathrm{Zn}>\mathrm{Cu}$. No presente estudo, a ordem de correspondência direta dos metais com o IMO foi $\mathrm{Cu}>\mathrm{Zn}>\mathrm{Cr}$, o que coincide pelo menos com os metais $\mathrm{Cu}$ e o $\mathrm{Zn}$ como principais inibidores competitivos em relação aos outros metais estudados.

O Zn pode ser encontrado de várias formas no solo, como em solução, complexado a compostos orgânicos solúvel, na forma trocável, retido em sítios da MO, ocluso em sesquióxidos hidratados, precipitado, imobilizado em restos orgânicos e inorgânicos e nas redes cristalinas dos minerais (Adriano, 1986).

Segundo Kabata-Pendias (2010), o Zn é o elemento mais comum e móvel no solo e é considerado uma forma de íons livres e complexos na solução do solo, mas várias outras espécies iónicas ocorrem de forma não 
especifica e são adsorvidas. Fatores importantes que controlam a mobilidade do $\mathrm{Zn}$ nos solos são muito semelhantes ao $\mathrm{Cu}$, mas o $\mathrm{Zn}$ parece ser a forma mais solúvel. Para Adriano (1986) e Kabata-Pendias (2010), o Cd e o Zn têm estruturas iônicas, eletronegatividades e propriedades químicas semelhantes, e por isso podem ocorrer naturalmente juntos em altas concentrações. Entre os cátions divalentes, o $\mathrm{Cu}$ forma o mais estável complexo com a MO em relação ao $\mathrm{Pb}$ e ao $\mathrm{Zn}$.

Os subpontos $\mathrm{P}_{1.1}$ (93,9 mg.kg-1) e $\mathrm{P}_{1.9}$ (112,9 mg.kg-1) apresentam-se acima do limite do VP (86,0 mg. $\mathrm{kg}^{-1}$ ) e limite background (89,55 mg. $\mathrm{kg}^{-1}$ ) para o metal Zn em relação aos demais subpontos que estão na faixa do VRQ (60,0 mg. $\left.\mathrm{kg}^{-1}\right)$ no $\mathrm{P}_{1}$. Com exceção dos subpontos $\mathrm{P}_{2.10}$ (48,9 mg.kg $\left.{ }^{-1}\right)$ e $\mathrm{P}_{2.13}(51,2$ $\mathrm{mg} \cdot \mathrm{kg}^{-1}$ ), que estão na faixa do limite do VRQ no $\mathrm{P}_{2}$, os demais subpontos estão próximos do VP. Estão acima do limite background (89,55 mg. $\left.\mathrm{kg}^{-1}\right)$ no $\mathrm{P}_{2}$ somente os subpontos $\mathrm{P}_{2.11}(92,0$ mg.kg $\left.{ }^{-1}\right), P_{2.14}\left(143,3\right.$ mg.kg $\left.{ }^{-1}\right)$ e $P_{2.18}(118,1$ mg. $\left.\mathrm{kg}^{-1}\right)$. O VI do Zn é de $1900,0 \mathrm{mg} \cdot \mathrm{kg}^{-1}$ e os valores não apresentam risco de intervenção agrícola.

Entre os metais analisados, o que demanda maior atenção quanto à toxicidade é o Cd, pois excedeu os limites VP e VI nas duas rodovias em pelo menos um subponto do conjunto de amostragem. Na sequência, vêm $\mathrm{Cu}$, Co e $\mathrm{Zn}$, que superaram o VP apenas em alguns subpontos. $\mathrm{O} \mathrm{Cu}$ excedeu os valores de VP na maioria dos subpontos do $\mathrm{P}_{2}$ e em alguns do $\mathrm{P}_{1}$. $\mathrm{O} \quad \mathrm{Pb}, \quad$ o $\quad \mathrm{Cr}$ e $\mathrm{o} \quad \mathrm{Ni}$ não apresentaram concentrações acima dos VP.

As concentrações dos metais que estão acima do VP em pelo menos um subponto do conjunto de amostragem indicam comprometimento da qualidade do solo nas áreas adjacentes às rodovias $\left(\mathrm{P}_{1} \mathrm{e} \mathrm{P}_{2}\right)$. Esses metais, associados à fração de $\mathrm{MO}$ do solo, geralmente formam complexos que evitam a absorção pelas plantas, mas é iminente seu carreamento até as águas do Córrego da Cascata. Por isso, esses locais devem ser monitorados constantemente para minimizar os efeitos dos produtos da combustão de veículos automotores e do desgaste dos seus componentes, que, carreados pelas chuvas, contaminam a região.

$\mathrm{Na}$ sequência deste trabalho, pretende-se avaliar o teor dos metais aqui estudados em sedimentos e a fitorremediação com uso de espécies bioacumuladoras de metais para a remoção desses contaminantes.

\section{CONCLUSÕES}

Pelo presente estudo constatou-se contaminação por espécies metálicas nas rodovias Domingos Sartori $\left(\mathrm{P}_{1}\right)$ e Marechal Rondon $\left(\mathrm{P}_{2}\right)$. Os produtos da combustão de veículos automotores e o desgaste de seus componentes foram considerados fontes primárias de contaminação por metais nessas rodovias. As áreas residenciais e a linha férrea, suspeitas de serem fontes secundárias, serão investigadas em estudo posterior.

Os resultados obtidos nos subpontos amostrados no $\mathrm{P}_{2}$ indicam maior contaminação (1,2 a 11,0 vezes) pelos metais $\mathrm{Cd}, \mathrm{Pb}, \mathrm{Cu}, \mathrm{Co}$, $\mathrm{Cr}$ e Zn. Os principais indícios do elevado teor de metais no $\mathrm{P}_{2}$ em relação ao $\mathrm{P}_{1}$ foram: rodovia mais antiga e com maior densidade (1,4 vezes) de veículos leves e pesados. Nos locais de coleta mais próximos e nos mais distantes das rodovias, os níveis dos metais $\mathrm{Cu}, \mathrm{Zn}$ e $\mathrm{Cr}$ indicaram maior biodisponibilidade pela sua relação positiva com o IMO. Os metais associados à fração da MO geralmente formam complexos que evitam a absorção pelas plantas, mas é iminente o carreamento desses poluentes até as águas do Córrego da Cascata, devido à sua proximidade em relação aos subpontos de amostragem. Nos subpontos intermediários, os níveis de metais encontrados foram altos e inversamente proporcionais à distância da rodovia. No $\mathrm{P}_{2}$, o Cd atingiu valores acima dos limites estabelecidos pela Cetesb, como o VP, que exige monitoramento constante, e o valor de intervenção agrícola (VI), pelo alerta de risco potencial de contaminação. $\mathrm{O} \mathrm{Cu}$, o Co e o Zn superaram o VP na maioria dos subpontos amostrais no $\mathrm{P}_{1}$ e $\mathrm{P}_{2}$. Somente o $\mathrm{Sb}$ não foi detectado em nenhuma das amostras. As demais espécies metálicas ( $\mathrm{Pb}, \mathrm{Cr}$ e $\mathrm{Ni}$ ) não apresentaram concentrações acima dos limites estabelecidos.

Assim, os metais com teores acima dos valores orientadores e de proteção em pelo menos um subponto no conjunto de amostras devem ser monitorados periodicamente para 
mitigar os efeitos dos produtos da combustão de veículos automotores e do desgaste de seus componentes, trazidos pelo ar atmosférico ou pelas águas de escoamento de chuva. Isso se torna necessário para melhorar a qualidade da água do Córrego da Cascata e da saúde da população ribeirinha e dos animais que vivem próximo a esse córrego.

\section{REFERÊNCIAS}

ADRIANO, D.C. Trace elements in the terrestrial environment. Aiken, South Carolina, USA, 533p, 1986.

BAGER, A. \& FONTOURA, V. Ecologia de estradas no Brasil contexto histórico e perspectivas futuras. In: BAGER, A. Ecologia de estradas: tendências e pesquisas. Lavras, p. 13-33, 2012.

BELÓ, A; QUINÁIA, S.P.; PLETSCH, A.L. Caracterização de sedimento superficial do rio Jordão na região Centro Sul do Paraná. Brasil. Revista Ambiágua, Taubaté, SP, v. 5, n. 1, p. 134-144, 2010.

BROSKA, C.Z.; ANDRADE, C.M.; ZANELLO, S.; MELO, V. D.F. Chumbo em solos às margens de estradas na região metropolitana de Curitiba. Revista Acadêmica de Ciências Agrárias. Ambientais, Curitiba, v. 8, n. 1, p. 47-53, 2010.

CETESB - Companhia de Tecnologia de Saneamento Ambiental. Decisão Diretória n. 45 de 20 de Fevereiro de 2014. Dispõe sobre a aprovação dos valores orientadores para Solos e águas subterrâneas no Estado de São Paulo, em substituição aos Valores Orientadores de 2005 e dá outras providências. Diário Oficial de 21 de fevereiro de 2014. v. 124, n.36, p. 53.

COTTA, J.A.O. Diagnóstico ambiental do solo e sedimento do Parque Estadual Turístico do Alto Ribeira (PETAR). São Carlos, 2003, 130p. Dissertação (Química Analítica) - Instituto de Química de São Carlos, Universidade de São Paulo.

DNIT - Departamento Nacional de Infra-Estrutura de Transportes. Ministério dos Transportes. Manual rodoviário de conservação, monitoramento e controle ambiental. Publicação. IPR - 711. Brasília: Diretoria de planejamento e pesquisa, Instituto de Pesquisas Rodoviárias, v. 68, p. 2005.

DUARTE, R.P.S. Avaliação do cádmio (Cd), chumbo (Pb), níquel (Ni) e zinco ( $\mathrm{Zn}$ ) em solos e plantas às margens de uma rodovia de tráfego intenso de veículos. Botucatu, 2003, 127p. Tese (Doutorado Agronomia) - Faculdade de Ciências Agronômicas, UNESP.

DUARTE, R.P.S. \& PASQUAL, A. Avaliação do cádmio (Cd), chumbo $(\mathrm{Pb})$, níquel $(\mathrm{Ni})$ e zinco ( $\mathrm{Zn})$ em solos, plantas e cabelos humanos. Revista Energia na Agricultura, Botucatu SP, v. 15, n. 1, p. 46-58, 2000.

FIGUEIREDO, E.M.M. Pontos críticos na caracterização físicoquímicas das águas de escorrência de estrada - Estudo de Caso do Projeto G-Terra. Viseu. 2011, 107p. Dissertação (Mestrado em Meio Ambiente) - Instituto Politécnico de Viseu. Escola Superior de Tecnologia e Gestão de Viseu.

GAN, H.; ZHUO, M.; LI, D.; ZHOU, Y. Quality characterization and impact assessment of Highway runoff in urban and rural área of Guangzhou, China. Environmental Monitoring and Assessment. v. 140, p. 147-159, 2008.

HOODA, P.S. Trace elements in soils. $1^{\mathrm{a}}$ Ed, London UK, Wiley, 596p, 2010

KABATA-PENDIAS, A. Trace elements in soil and sand plants, $4^{\mathrm{TH}}$ Ed., Boca Raton FL, 505p., 2010.

KAYHANIAN, M.; STRANSKYB, C.; BAYAC, S; LAUD, S.L.; STENSTROMD, M.K. Toxicity of urban highway runoff withre specttostorm duration, Science Total Environment. p. 386-406, 2008.

KELLER, C. \& VÉDY, J.C. Distributions of copper and cadmium fractions in two Forest soils. Journal of Environmental Quality. Madison, v. 23, n. 5, p. 987-999, 1994.

LEITÃO, T.E.; FERREIRA, J.P.L.; SMETS, S.; DIAMANTINO, C.A. Poluição ambiental causada por estradas. O projeto Polmit.
In: CONGRESSO RODOVIÁRIO PORTUGUÊS, Portugal, 2000. Comunicação...Portugal, 2000.

LOPES JÚNIOR, I. Atlas geoquímico do Vale do Ribeira: geoquímica dos sedimentos ativos de corrente. $2^{\mathrm{a}}$ Ed. Revista São Paulo: CPRM, 2007, 77 p.

MARKUS, J. \& McBRATNEY, A.B.A. Reviw of the contamination of soil with. Lead II, spacial distribution and risk sassesment of soil lead. Environment International, v. 27, p. 399-411, 2001.

MARTINEZ, L.L.G. Distribuição de poluição difusa por sedimentos urbana em áreas impermeáveis. Rio Grande do Sul RS, 2010, 90p. Dissertação (Mestrado em Recursos Hídricos e Saneamento Ambiental), Universidade Federal do Rio Grande de Sul.

MATOS, A.T. Poluição ambiental: impactos no meio físico. 2 ed., Viçosa: UFV, 260p., 2011.

MINELLO, M.C.S.; PAÇÓ, A.L.; MARTINES, M.A.U.; CAETANO, L.; SANTOS, A. DOS; PADILHA, P.M.; CASTRO, G.R. Sediment grain size distribution and heavy metals determination in a dam on the Paraná River at Ilha Solteira, Brazil, Journal of Environmental Science and Health. Part. 44, p. 861-865, 2009.

MINEROPAR - Minerais do Paraná S. A. Atlas Geoquímico do Estado do Paraná. Curitiba: Mineropar, 80p., 2001.

MINEROPAR - (Minerais do Paraná S. A.). Geoquímica do solo. Relatório Final, Curitiba: Mineropar, 409 p., 2005.

PINTO, C.A. Estudo da estabilização por solidificação de resíduos contendo metais pesados. São Paulo, 2005, 229p. Tese (Doutorado em Engenharia Química), Escola Politécnica da Universidade de São Paulo.

RODRIGUES, A.S.L. \& NALINI JÚNIOR, H.A. Valores background geoquímicos e suas implicações em estudos ambientais. Revista Geociências, Ouro Preto, MG, v. 62, n. 2, p. 155-165, 2009.

SANTOS, T.O.; VIEIRA, R.; SILVA FILHO, C.A.; AZIN, C.A., VALENTIN, E. Quantificação de elementos químicos associados ao tráfego de veículos em bromélias atmosféricas transplantadas na Região Metropolitana do Recife. Revista Scientia Plena, U.F. Sergipe, v. 9, n. 8, p. 1-8, 2013.

SILVA, L.C.; ALMEIDA, J.C.R.; SILVA ALMEIDA, A.A. Ocorrência de chumbo e zinco nos solos e plantas às margens de uma rodovia de tráfego veicular intenso. Revista Ambiente Água, Taubaté, v. 8, p. 50-59, 2013.

SOKAL, R.R \& ROHLF, F.J. Biometry: the principles and practice of statistics in biological research. $3^{\text {rd }}$. ed. New York: W. H. Freeman. 887p., 1995

VINHAL-FREITAS, I.C.; MALDONADO, A.C.D.; ALVARENGA, C.B.; CAMARGO, R.; WENDLING, B. Adsorção e dessorção de metais no solo e coeficientes de isotermas de Freundlich e Langnuir. Agropecuária Técnica, Areia, v. 31, n. 2, p 153-163, 2010.

YANNOPOULOS, S.; BASBAS, S.; GIANNOPOULOU, I. Water bodies pollution due to highways storm water runoff: Measure sand legislative framework. Global NEST. Journal, Greece, v. 15, n. 1, p. 85-92, 2013

Submetido em 20 de dezembro de 2016 Aceito em 5 de fevereiro de 2018 